Горбань Александр Сергеевич

преподаватель кафедры криминалистики и правовой информатики

Кубанского государственного университета

\section{ВЫДВИЖЕНИЕ И ПРОВЕРКА ВЕРСИЙ О ВЕРБАЛЬНЫХ ИНСЦЕНИРОВКАХ ПРИ ПРОИЗВОДСТВЕ ДОЗНАНИЯ В СОКРАЩЕННОЙ ФОРМЕ}

\section{Аннотация}

В статье рассматриваются проблемные вопросы выдвижения и проверки версий при производстве рассмотрения сообщения о преступлении и расследовании преступлений в сокращенной форме. Поскольку целью указанной формы является производство расследования в сравнительно небольиие сроки при упрощенных требованиях к собиранию, проверке и оценке доказательственной информации, это может подтолкнуть правоприменителя к выдвижению и проверке версии лишь о виновности лица, не допуская тем самым возможности использования сокращенной формы дознания в качестве инструмента для уклонения от ответственности. С учетом этого и других обозначенных в статье негативных обстоятельств предложена конкретизированная система версий при рассмотрении проверочных материалов и последующем дознании по преступлениям небольшой тяжести, в отношении которых возможна перспектива расследования в сокращенной форме.

Ключевые слова:

сокращенная форма дознания, противодействие расследованию, вербальные инсиенировки, проверочные версии.

\section{Gorban Alexander Sergeyevich}

Lecturer, Criminalistics and Legal Informatics Department, Kuban State University

\section{SETTING OUT AND VERIFICATION OF LEADS ON VERBAL STAGING IN THE ABBREVIATED INQUIRY}

Summary:

The article deals with the problematic issues of setting out and verification of leads in the consideration of crime reports and investigation of crimes in abbreviated form. Since the purpose of this form is investigation in a relatively short period of time with simplified requirements for the collection, verification and evaluation of the evidentiary information, it could prompt the law enforcer to set out and verify only the leads of person's guilt, thereby avoiding the possibility of using the abbreviated inquiry as a tool for evasion of responsibility. In view of this and other adverse circumstances discussed in the article, the author presents a specified system of leads used when considering verifying materials and subsequent investigation of minor offenses, which can be investigated in abbreviated form.
Keywords: investigation in abbreviated form, counteracting to investigation, verbal staging, verified lead.

Криминалистическая версия уже давно стала неотъемлемым структурным элементом методики расследования отдельных видов преступлений. Необходимо обратить внимание в том числе и на достаточно полное исследование этой частной криминалистической теории, проблемные вопросы которой в разное время освещали Г.В. Арцишевский, Р.С. Белкин, Л.Я. Драпкин, А.М. Ларин, И.М. Лузгин, Я. Пещак, А.А. Хмыров, А.А. Эйсман и др. [1]. На современном этапе вопросы логической конструкции, правил построения и проверки версий подробно рассмотрены в работах А.В. Руденко [2]. Несмотря на многообразие научных определений, предлагаемых учеными-криминалистами, автор данной работы считает предпочтительным использовать понятие версии, данное А.В. Руденко: «...Обоснованное и логически правильное предположительное объяснение сущности преступления и связей между механизмом совершения преступления и обнаруженными следами».

Поскольку версия представляет собой разновидность гипотезы, которая является формой развития знаний, обоснованным предположением, выдвигаемым с целью выявления свойств и причин исследуемых явлений [3], это подразумевает ее выдвижение любым субъектом практически в любой сфере науки или практической деятельности. Криминалистическая версия имеет определенную специфику в силу того, что представляет собой разновидность частной гипотезы, отличающейся от иных частных гипотез по следующим основаниям:

- конструируется и используется в специфической сфере общественной практики - уголовном судопроизводстве;

- объясняет фракты и обстоятельства, имеющие значение для установления истины по делу;

- должна быть проверена в ограниченный законом срок;

- проверяется специфическими методами, обусловленными законом; 
- проверяется в условиях, когда возможно активное противодействие такой проверке со стороны заинтересованных в сокрытии истины лиц. Версия как разновидность гипотезы либо в конце концов приводит к установлению достоверности, либо отпадает, опровергается [4].

Немаловажным является тот фракт, что криминалистическая версия взаимообусловлена другим важным элементом - следственной ситуацией, поскольку, как отмечает Т.С. Волчецкая, способствует выдвижению обоснованных следственных версий, определению дальнейших путей расследования; выбору оптимального сочетания и последовательности проведения следственных действий и оперативно-разыскных мероприятий; использованию наиболее целесообразных направлений взаимодействия следователя с органами дознания, иными службами; разработке наиболее эффективных тактических приемов, комбинаций и операций; выявлению причин и условий, способствующих совершению преступлений [5].

Рассматривая вопрос о выдвижении версий в ходе производства расследования в сокращенном порядке, можно обнаружить следующие изъятия:

1. Требования ст. 226.5 УПК РФ, а также полученная в ходе проверки сообщения о преступлении доказательственная информация позволяют субъекту доказывания, в данном случае дознавателю, не исследовать субъект и субъективную сторону преступления, следовательно освобождая его от выдвижения версий по элементам состава, что может нести под собой определенное противоречие, выражающееся в следующем: «Выдвижение версий о мотивах и цели преступления является обязательным во всех без исключения случаях. К установлению этих обстоятельств обязывает не только прямое требование закона (п. 2 ст. 73 УПК), но и существенное практическое соображение: само по себе наличие мотива и цели является уликой, указывающей на совершителя преступления...» [6].

2. Расследование преступлений, указанных в ч. 3 ст. 150 УПК РФ (в том числе совершенных в условиях очевидности), как в общем, так и в сокращенном порядке дознания, как правило, не представляет сложности, поскольку с самого начала расследования известен фракт совершения преступления конкретным лицом (лицами). Этим требованиям содержательно соответствуют простые следственные ситуации. По этой причине может показаться, что необходимость в выдвижении каких-либо версий может быть полностью исключена. С практической точки зрения это предположение опровергается следующими фрактами:

- во-первых, в методических рекомендациях, посвященных особенностям расследования преступлений в сокращенной форме, одним из необходимых условий, влияющих на окончание данной формы расследования в части проверки и оценки собранных доказательств, является наличие в деле непроверенных и неопровергнутых версий, кроме основной [7];

- во-вторых, трудно согласиться с тем фактом, что дознаватель не допускает в орбиту своего познания только очевидные факты.

Так как возможность использования сокращенного порядка дознания зависит от позиции подозреваемого, дознаватель, в распоряжение которого передается возбужденное уголовное дело, зависит от достаточности собранных на этапе рассмотрения сообщения о преступлении доказательств. Их совокупность при корректном использовании способна преодолеть прогнозируемую защитную позицию и сформировать у последнего убеждение в целесообразности и выгоде перехода к сокращенному дознанию или же укрепить уверенность в принятом в ходе рассмотрения сообщения о преступлении решения.

Тем не менее, приступая к подготовке к допросу подозреваемого, в отношении которого может быть избран сокращенный порядок дознания, дознаватель должен располагать информацией в том числе и о том, что в сведениях, полученных в ходе опроса заявителя, потерпевшего, очевидцев преступного события и заподозренного лица, отсутствуют факты добросовестного заблуждения и, что может осложнить расследование и производство следственных действий после возбуждения уголовного дела, - сокрытия криминалистически значимой информации путем ее намеренного искажения или утаивания.

Другим негативным обстоятельством, обнаружение которого может послужить препятствием для применения норм о сокращенном порядке дознания, является самооговор подозреваемого. Показательно, что с появлением в УПК РФ положений о сокращенном дознании многие авторы вновь обратились к необходимости своевременного диагностирования и разоблачения такого способа противодействия расследованию [8].

Причины и мотивы самооговора в разное время подвергались исследованию в работах А.Р. Ратинова и Т.А. Скотниковой, И.А. Николайчука [9].

В научной литературе выделяют полный самооговор, под которым понимается абсолютная непричастность субъекта к совершению расследуемого преступления, и частичный - самооговор по факту несовершения субъектом действий и отягчающих обстоятельств. Основаниями подозрения лица в применении такого способа вербальной инсценировки являются [10]: 
- связь с жертвой или предметом преступного посягательства;

- связь с местом преступления или пребывание на этом месте;

- наличие мотивов и заинтересованности в наступлении преступного результата;

- владение средствами, пригодными для совершения преступления, плодами преступления или подобными им;

- наличие следов, могущих указывать на совершение преступления данным лицом;

- совпадение примет данного лица с приметами преступника;

- совершение данным лицом аналогичных действий в прошлом;

- наличие нравственно-психологических особенностей, подобных тем, которыми обладал преступник; ление;

- принадлежность к той же группе, к которой принадлежало лицо, совершившее преступ-

- обнаружение виновной осведомленности, боязни ответственности;

- личная заинтересованность ходом расследования;

- создание препятствий для установления истины по делу [11].

Как отмечает И.А. Николайчук, среди других оснований, побуждающих лицо прибегнуть к самооговору, могут быть:

- воздействие на субъект со стороны лидера или членов преступного сообщества с целью смягчения, отрицания их вины либо инсценирование полного отсутствия соучастников;

- признание в совершении незначительного вымышленного преступления с целью уклонения от ответственности за совершение более тяжкого действительного;

- признание в совершении преступления (в том числе вымышленного), к которому субъект непричастен, с целью временного заключения под стражу, которое может послужить средством защиты от действительных или мнимых посягательств со стороны иных лиц;

- самооговор с целью попасть в условия изоляции от общества, условия которой будут способствовать избавлению от наркотической или алкогольной зависимости;

- самооговор вследствие психических заболеваний;

- самооговор вследствие принуждения к нему сотрудниками правоохранительных органов, использующими незаконные методы расследования [12].

Перечень этих оснований необходимо дополнить следующими:

- стремление приобрести авторитет в преступной среде, «угодить» следователю, признавшись в совершении других аналогичных и ранее не раскрытых преступлений;

- желание облегчить свое положение, получить какие-либо выгоды от лица, производящего расследование и рассмотрение уголовного дела, чему способствуют ложные и реальные обещания данных лиц (изменить меру пресечения на менее строгую, улучшить условия содержания под стражей, смягчить наказание и пр.);

- намерение ввести следствие в заблуждение, запутать и затянуть его, в надежде в дальнейшем отказаться от своих показаний и избежать ответственности как за действительно совершенное, так и за мнимое преступление [13];

- намеренное выражение согласия на производство сокращенного дознания и особого порядка принятия судебного решения.

Подобное решение может являться следствием вышеупомянутых причин (уклонения от ответственности за более тяжкое преступление, констатации факта единоличного совершения преступления при отсутствии соучастников). В этой ситуации сокращенный порядок дознания будет являться удобным инструментом, поскольку при согласии подозреваемого наказание не будет превышать одну вторую от максимального срока или размера, предусмотренного санкцией статьи Уголовного кодекса РФ.

Проверка достоверности сведений, отобранных в ходе опросов, на предмет добросовестного заблуждения лица направлена на подтверждение общей версии в отношении события преступления, равно как обнаружение и фиксация предметов и следов, связанных с преступным событием, также могут быть направлены на установление мотивов подачи заявления, явки с повинной.

Однако в силу специфики этапа предварительной проверки сообщения о преступлении, которую составляют информационная недостаточность, направленность усилий на установление объекта и объективной стороны, даже при возникновении доследственной ситуации, когда заподозренное лицо задержано с поличным и не отрицает своей вины в совершении преступных действий, такие версии будут носить характер проверочных. Понятие проверочных версий впервые было разработано и использовано в работах А.М. Ларина [14] и В.В. Степанова [15].

Среди основных отличий проверочных версий от следственных называют: 
- различные цели и задачи. Целью проверочных версий является установление достаточных данных, необходимых для возбуждения уголовного дела или принятия решения об отказе, вторых - установление обстоятельств, подлежащих доказыванию;

- различный объем. Проверочные версии уже по объему и выдвигаются в отношении наличия или отсутствия признаков преступления и их достаточности. Могут быть также выдвинуты в отношении мотивов подачи заявления о преступлении, законности повода для возбуждения уголовного дела;

- различные сроки проверки;

- различные средства проверки.

Сходство проверочных версий со следственными проявляется в общих субъектах выдвижения, делении по кругу объясняемых событий на общие и частные, по степени определенности на типичные и конкретные [16].

Учитывая указанные выше негативные обстоятельства этапа рассмотрения сообщения о преступлении, возможно выдвижение следующих типичных проверочных версий:

1. Преступление совершено лицом, в отношении которого производятся проверочные действия в связи с рассмотрением сообщения о нем.

2. Лицо, в отношении которого производятся проверочные действия, оговаривает себя.

3. Заявитель или иное лицо, сообщившее о преступлении, намеренно оговаривает проверяемого.

Также могут быть выдвинуты частные версии в отношении:

1) возможных соучастников у лица, в отношении которого ведутся проверочные действия,

2) мотива устного или письменного заявления о преступлении,

3) орудия, места, способа совершения преступления.

Следует помнить, что правила выдвижения требуют выдвижения не только основной, но и контрверсии. Применительно к обозначенной выше классификации основной версией будет являться предположение о совершении проверяемым лицом преступления. Контрверсией будет служить предположение о самооговоре или оговоре проверяемого лица заявителем.

В случае принятия решения о возбуждении уголовного дела субъекту, осуществлявшему рассмотрение сообщения о преступлении, рекомендуется составить план, включив в него выдвинутые и опровергнутые проверочные версии с указанием средств их проверки. Принимая во внимание ограничения стадии рассмотрения сообщения по срокам (3-5 суток), задачам (установление достаточных данных, обстоятельств, подлежащих доказыванию) и загруженность дознавателя материалами расследуемых уголовных дел, такими средствами будут являться: опрос задержанного лица, потерпевшего, очевидцев, осмотр места происшествия, производство экспертиз, истребование характеризующих материалов.

Если в ходе предварительной проверки в распоряжении субъекта, осуществляющего расследование, окажутся факты, косвенно свидетельствующие о самооговоре проверяемого лица, подтверждающие жизнеспособность контрверсии, но в силу определенных ограничений по средствам проверки осуществить ее отработку до конца не представится возможным, то эту проблему также рекомендуется изложить в плане, на основе которого дознаватель, в распоряжение которого поступят проверочные материалы, смог своевременно принять организационные решения (поручения проведения оперативно-разыскных мероприятий, привлечение участкового уполномоченного, специалистов), произвести следственные действия (например, обыск, проверку показаний на месте), принять на их основе тактические решения.

Таким образом, при подготовке к первому допросу подозреваемого дознаватель может столкнуться с двумя версиями: о виновности и о самооговоре, вне зависимости от того, был ли он задержан по «горячим следам» или на месте совершения преступных действий. Параллельная проверка каждой из перечисленных версий и отражение в плане проверки средств и результатов помогут свести к минимуму возможность возврата для производства дополнительных следственных действий и собирания доказательств уполномоченными лицами - начальником подразделения дознания, прокурором.

Практическая значимость обозначенной иерархии версий будет проявляться в обеспечении конкретности работы субъектов, осуществляющих рассмотрение проверочных материалов и последующее дознание по преступлениям небольшой тяжести, в отношении которых возможна перспектива расследования в сокращенной форме.

\section{Ссылки:}

1. Арцишевский Г.В. Выдвижение и проверка следственных версий. М., 1978 ; Белкин Р.С. Курс криминалистики : в 3 т. Т. 2: Частные криминалистические теории. М., 1997. С. 372 ; Его же. Теория доказательств в советском уголовном процессе. Общая часть. М., 1966. С. 318 ; Драпкин Л.Я. Построение и проверка следственных версий : авторефрерат 
дис. ... канд. юрид. наук. М., 1972 ; Ларин А.М. От следственной версии к истине. М., 1976 ; Лузгин И.М. Построение и проверка версии при производстве расследования по уголовному делу // Вопросы криминалистики. М., 1963. Вып. 8. С. 5 ; Пещак Я. Следственные версии. М., 1976 ; Хмыров А.А. Теория доказывания. Общая часть : учеб. пособие. Краснодар, 2006 ; Эйсман А.А. Логика доказывания. М., 1971

2. См.: Руденко А.В.: 1) Логические правила проверки версий // Теория и практика общественного развития. 2010 . № 4. С. 178 ; 2) Понятие криминалистической версии // Черные дыры в российском законодательстве. 2010. № 4. С. 119121 ; 3) Содержательная логика доказывания. М., 2011.

3. Кириллов В.И., Старченко А.А. Логика : учебник. 6-е изд., перераб. и доп. М., 2008. С. 213.

4. Руденко А.В. Содержательная логика доказывания. С. 34.

5. Волчецкая Т.С. Криминалистическая ситуалогия : монография / под ред. Н.П. Яблокова. М. ; Калининград, 1997. C. $109-110$.

6. Руденко А.В. Содержательная логика доказывания. С. 60.

7. Науменко О.А. Особенности расследования преступлений в сокращенной форме дознания : метод. рек. Краснодар, 2014. C. 19.

8. См.: Кузнецов А.Н. Доказывание самооговора и другие аспекты регулирования дознания в сокращенной форме // Труды Академии управления МВД России. 2015. № 2 (34). С. 50-53 ; Моисеев Н.А., Новоселов Н.Г. К вопросу о противодействии раскрытию и расследованию преступлений лицами, совершившими преступление // Новая наука: проблемы и перспективы. 2016. № 6-3 (85). С. 275-283 ; Муравьев К.В., Воронов Д.А. Самооговор при производстве дознания в сокращенной форме и право на реабилитацию // Актуальные проблемы борьбы с преступлениями и иными правонарушениями. 2013. № 11-1. С. 165-167 ; Смолькова И.В. Самооговор как разновидность показаний обвиняемого // Сибирские уголовно-процессуальные и криминалистические чтения. 2016. № 3 (11). С. 43-50; Центров Е.Е. Недостатки изложения тактических особенностей проверки показаний на месте // Законность. 2016. № 7 (981). С. $47-53 ; и$ пр.

9. См.: Николайчук И.А. Сокрытие преступлений как форма противодействия расследованию. М., 2000 ; Ратинов А.Р., Скотникова Т.А. Самооговор (происхождение, предотвращение и разоблачение ложных признаний). М., 1973.

10. Николайчук И.А. Указ. соч. С. $70,111$.

11. Ратинов А.Р., Скотникова Т.А. Указ. соч. С. 103-104.

12. Николайчук И.А. Указ. соч. С. 122-123.

13. Тактика допроса на досудебном следствии : учеб. пособие / под общ. ред. В.Д. Зеленского. Краснодар, 2015. С. 40.

14. Ларин А.М. Работа следователя с доказательствами. М., 1966. С. 100-105.

15. Степанов В.В. Расследование взяточничества. Саратов, 1966. С. 27.

16. Ильин А.Н. Тактика предварительной проверки сообщения о преступлении : дис. ... канд. юрид. наук. М., 2008. C. $109-111$

\section{References:}

Artsishevsky, GV 1978, Nomination and verification of investigative leads, Moscow, (in Russian)

Belkin, RS 1966, Evidence theory in the Soviet criminal process. General conditions, Moscow, p. 318, (in Russian).

Belkin, RS 1997, Criminalistics course, in 3 vols., vol. 2, Moscow, p. 372, (in Russian).

Drapkin, LYa 1972, Construction and verification of investigative leads, PhD in Law thesis abstract, Moscow, (in Russian).

Eisman, AA 1971, The logic of proof, Moscow, (in Russian).

Ilyin, AN 2008, The tactics of the preliminary verification of the crime report, PhD in Law thesis, pp. 109-111, (in Russian).

Khmyrov, AA 2006, Evidence theory. General conditions, manual, Krasnodar, (in Russian).

Kirillov, VI \& Starchenko, AA 2008, Logic, textbook. 6th ed., Moscow, p. 213, (in Russian).

Kuznetsov, AN 2015, 'Proving self-incrimination and other aspects of inquiry regulation in a reduced form', Trudy Akademii upravleniya MVD Rossii, no. 2 (34), pp. 50-53, (in Russian).

Larin, AM 1966, Work of the investigator with evidence, Moscow, pp. 100-105, (in Russian).

Larin, AM 1976, From the investigative lead to the truth, Moscow, (in Russian).

Luzgin, IM 1963, 'Construction and verification of the lead in the investigation of the criminal case', Voprosy kriminalistiki,

Moscow, Issue 8, p. 5., (in Russian).

Moiseev, NA \& Novoselov, NG 2016, 'On the issue of counteraction to the disclosure and investigation of crimes committed by offender', Novaya nauka: problemy i perspektivy, no. 6-3 (85), pp. 275-283, (in Russian).

Muraviev, KV \& Voronov, DA 2013, 'Self-incrimination in the production of an inquiry in a reduced form and the right to rehabilitation', Aktual'nyye problemy bor'by s prestupleniyami i inymi pravonarusheniyami, no. 11-1, pp. 165-167, (in Russian).

Naumenko, OA 2014, Features of investigation of crimes in the reduced form of inquiry, manual, Krasnodar, p. 19, (in Russian). Nikolaychuk, IA 2000, Concealing crimes as a form of counteraction to investigation, Moscow, (in Russian).

Peshchak, Ya 1976, Investigative leads, Moscow, (in Russian).

Ratinov, AR \& Skotnikova, TA 1973, Self-incrimination (origin, prevention and exposure of false confession), Moscow, (in Russian).

Rudenko, AV 2010a, 'Logical rules for verifying leads', Teoriya i praktika obshchestvennogo razvitiya, no. 4, p. 178, (in Russian).

Rudenko, AV 2010b, 'The concept of criminal lead', Chernyye dyry v rossiyskom zakonodatel'stve, no. 4, pp. 119-121, (in Russian).

Rudenko, AV 2011, Substantive logic of the proof, Moscow, (in Russian).

Smolkova, IV 2016, 'Self-incrimination as a kind of evidence of the accused', Sibirskiye ugolovno-protsessual'nyye $i$ kriminalisticheskiye chteniya, no. 3 (11), pp. 43-50, (in Russian).

Stepanov, VV 1966, Investigation of bribery, Saratov, p. 27, (in Russian).

Tsentrov, EE 2016, 'The disadvantages of the tactical features presentation of verification of evidence at the place', Zakonnost', no. 7 (981), pp. 47-53, (in Russian).

Volchetskaya, TS \& Yablokov, NP (ed.) 1997, Criminal situation, monograph, Moscow, Kaliningrad, pp. 109-110, (in Russian). Zelensky, VD (ed.) 2015, The tactics of interrogation at the pre-trial investigation, study guide, Krasnodar, p. 40, (in Russian). 